with a view to cure possible. The results in this radical group, however, show the major part played by timely operation in colorectal cancer. Most deaths in this group were from liver metastases which were occult at the time of operation: hence adjuvant chemotherapy-possibly by postoperative portal-vein infusion ${ }^{10}$-may further improve the results of operation.

Can anything be done for the half who present with ineradicable disease? The only action available at present is to achieve earlier diagnosis. That a long history before diagnosis does not adversely affect outcome only underlines the variability of malignancy between one patient and another. Knowing that a carcinoma is probably present for five years before it is clinically recognised ${ }^{11}$ is a great stimulus to act on any suspicion of carcinoma and to initiate useful investigations. Some patients still report to the outpatient department only after they have complained for months of rectal bleeding or diarrhoea, and several of these have a palpable rectal tumour. Hospital doctors must remember the vital role of sigmoidoscopy in diagnosing rectal neoplasms just out of reach of the finger, the great importance of adenomas of the rectum or sigmoid, ${ }^{11}$ and that single contrast barium enemas may be misleading (and even double contrast enemas be difficult to interpret) in the proximal colon. ${ }^{12}$

Although results may not have changed much in the past 20 years, it is important not to be fatalistic about the outcome of colorectal cancer, especially since timely operation can produce . such useful long-term benefit.

We thank our colleagues for permission to examine case notes of their patients. We are grateful for the willing and expert secretarial help provided by Mrs J Amonoo.

\section{References}

${ }^{1}$ Doll R, Muir C, Waterhouse JAH. Cancer incidence in five continents. Vol 2. Berlin: Springer Verlag, 1970.

${ }^{2}$ Lanier AP, Wychulis AR, Dockerty MB, Elveback LR, Beahrs OH, Kurland LT. Colorectal cancer in Rochester, Minnesota 1940-1969. Cancer 1973;31:606-15.

${ }^{3}$ Elliot MS, Louw JH. A 10-year survey of large bowel carcinoma at Groote Schuur Hospital with special reference to patients under 30 years of age. Br 7 Surg 1979;66:621-4.

${ }^{4}$ Slaney G. Results of treatment of carcinoma of the colon and rectum. In: Irvine WT, ed. Modern trends in surgery 3. London: Butterworths, 1971: 69-89.

${ }^{5}$ Cooke RV. Advanced carcinoma of the colon with emphasis on the inflammatory factor. Ann R Coll Surg Engl 1956;18:46-61.

${ }^{6}$ Berge T, Ekelund G, Mellner C, Pihl B, Wenekert A. Carcinoma of the colon and rectum in a defined population. Acta Chir Scand [Suppl] $1973 ; 438$.

${ }^{7}$ Cutler SJ. Trends in cancers of the digestive tract. Surgery 1969;65: $740-52$.

${ }^{8}$ Lockhard-Mummery HE, Ritchie JK, Hawley PR. The results of surgical treatment for carcinoma of the rectum at St Mark's Hospital from 1948 to 1972 . Br F Surg 1976;63:673-7.

${ }^{9}$ Whittaker M, Goligher JC. The prognosis after surgical treatment of carcinoma of the rectum. Br F Surg 1976;63:384-8.

10 Taylor I, Brooman P, Rowling JT. Adjuvant liver perfusion in rectal cancer: initial results of a clinical trial. $\mathrm{Br}$ Med $\mathcal{F} 1977$;ii:1320-2.

${ }_{11}$ Morson BC. Introduction: In: Morson BC, ed. The pathogenesis of colorectal cancer. (Vol 10 in Bennington JL, ed. Major problems in pathology.) Philadelphia: W B Saunders, 1978:1-13.

${ }^{12}$ Holliday HW, Hardcastle JD. Delay in diagnosis and treatment of symptomatic colorectal cancer. Lancet 1979 ;i:309-11.

${ }^{13}$ Waterhouse JAH. Cancer handbook of epidemiology and prognosis. London: Churchill Livingstone, 1974:4.

(Accepted 27 November 1979)

\title{
Synergistic effects of a combined salbutamol-nitroprusside regimen in acute myocardial infarction and severe left ventricular failure
}

\author{
MICHAEL B FOWLER, ADAM D TIMMIS, DOUGLAS A CHAMBERLAIN
}

\section{Summary and conclusions}

The haemodynamic effects of a simultaneous infusion of salbutamol and nitroprusside were measured in 20 patients with acute myocardial infarction and severe left ventricular failure. Six patients also had clinical manifestations of cardiogenic shock. Ten patients received salbutamol first with the subsequent addition of nitroprusside; in the other 10 patients nitroprusside was infused first. Salbutamol was infused at a constant rate of $20 \mu \mathrm{g} / \mathrm{min}$ in all patients, while the dose of nitroprusside, which averaged $51.25 \mu \mathrm{g} / \mathrm{min}$, was adjusted to reduce left ventricular filling pressure (measured as pulmonary artery end-diastolic pressure) to approximately $15 \mathrm{~mm} \mathrm{Hg}$ with reference to sternal angle.

Cardiac index increased in all patients from a mean of 1.8 to $2.6 \mathrm{l} / \mathrm{min} / \mathrm{m}^{2}$ while pulmonary artery end-diastolic pressure fell significantly from 24 to $16 \mathrm{~mm} \mathrm{Hg}$. The adverse effects were small in most patients: heart rate

Department of Cardiology, Royal Sussex County Hospital, Brighton MICHAEL B FOWLER, MB, MRCP, research registrar ADAM D TIMMIS, MB, MRCP, cardiac registrar

DOUGLAS A CHAMBERLAIN, MD, FRCP, consultant cardiologist did not increase significantly and systolic arterial pressure fell on average from 112 to $96 \mathrm{~mm} \mathrm{Hg}$. Ten of the 20 patients survived to leave hospital.

Nitroprusside accounted for most of the fall in filling pressure irrespective of treatment sequence, whereas both drugs contributed to the augmented cardiac output. The haemodynamic benefits of this combined regimen were considerably greater than those achieved by either drug alone. Thus salbutamol and nitroprusside have synergistic effects which influence favourably the two principal manifestations of left ventricular dysfunction after extensive myocardial infarction.

\section{Introduction}

Salbutamol is a relatively specific $\beta_{2}$-adrenergic receptor agonist with important haemodynamic effects due principally to reduction in peripheral arteriolar tone. ${ }^{1}$ The drug improves cardiac output in patients with severe left ventricular dysfunction after myocardial infarction but has little effect on left ventricular filling pressure. ${ }^{2}$ Most patients with a critical haemodynamic state after infarction have both reduced output and pulmonary oedema with excessive filling pressure; salbutamol is therefore of limited value. Nitroprusside has been recommended because it reduces both arteriolar and venous tone and decreases filling 
pressure. ${ }^{3-6}$ We therefore compared the effects of the two drugs in patients with myocardial infarction complicated by acute left ventricular failure, and also used both concurrently to determine whether they had a favourable synergistic action.

\section{Patients and methods}

Twenty patients were studied. The $17 \mathrm{men}$ and three women had an average age of 63 years (range 46 to 84 ). All had electrocardiographic evidence of acute myocardial infarction (18 anterior and two inferior) and radiographic evidence of pulmonary oedema. During the study period patients were sedated as necessary with diazepam and given continuous oxygen treatment; one was receiving a lignocaine infusion at a constant rate of $1.5 \mathrm{mg} / \mathrm{min}$. Seventeen patients had not improved on treatment with digoxin and frusemide. One patient was in atrial fibrillation and the rest were in sinus rhythm.

Observations were made in the coronary care unit within 36 hours of admission. Radial artery and right heart pressures and cardiac output were measured as described. ${ }^{2}$

The variation in cardiac output within any set of readings for the 19 patients in sinus rhythm did not exceed $0.41 / \mathrm{min}(0.6 \mathrm{l} / \mathrm{min}$ for the patient with atrial fibrillation). Peripheral resistance was calculated in arbitrary units as mean arterial pressure in $\mathrm{mm} \mathrm{Hg}$ divided by cardiac output in $1 / \mathrm{min}$. Stroke work index $\left(\mathrm{g} \mathrm{m} / \mathrm{m}^{2}\right)$ was calculated as the difference between mean arterial pressure and pulmonary artery end-diastolic pressure in $\mathrm{mm} \mathrm{Hg}$ multiplied by stroke index $\left(\mathrm{ml} /\right.$ beat $\left./ \mathrm{m}^{2}\right)$ multiplied by 0.0144 .

Salbutamol and nitroprusside were each diluted in 5\% dextrose and administered by infusion pumps (Watson Marlow Ltd) through separate cannulae in forearm veins. In the first 10 patients salbutamol was infused at a rate of $20 \mathrm{\mu g} / \mathrm{min}$ and haemodynamic measurements were made after 15 minutes. Nitroprusside $25 \mu \mathrm{g} / \mathrm{min}$ was then added with further increments of $25 \mu \mathrm{g} / \mathrm{min}$ every 15 minutes until pulmonary artery end-diastolic pressure had fallen to $15 \mathrm{~mm} \mathrm{Hg}$ or systolic blood pressure had fallen to $90 \mathrm{~mm} \mathrm{Hg}$. In the next 10 patients the order in which the drugs were given was reversed. Thus incremental doses of nitroprusside were given until pulmonary artery end-diastolic pressure or blood pressure had achieved the same endpoints, and salbutamol $20 \mu \mathrm{g} / \mathrm{min}$ was added. Haemodynamic measurements were made in the control state and before any change in drug doses. The condition of 11 patients allowed for temporary withdrawal of treatment, and further haemodynamic measurements were made 30 minutes later. At the end of the study the most favourable combination of salbutamol and nitroprusside was continued and other drugs were added as necessary.

The data for salbutamol alone from the first four patients were included in a previous communication. ${ }^{2}$

The reasons for the infusions and observations were explained to the patients, but we did not ask for written consent. We believe that this was in the best interests of the patients since our main aim was to plan effective treatment on an individual basis. A more formal approach might have increased both anxiety and risk. The protocol was approved by the ethical committee.

Calculated stroke work index was used as a guide to prognosis.? Student's $t$ test for paired data was used for statistical comparisons.

\section{Results}

The maximum infusion rate of nitroprusside for each patient ranged from 25 to $100 \mu \mathrm{g} / \mathrm{min}$ (average 51.25 ) before an endpoint was reached, while the dose of salbutamol was held constant at $20 \mu \mathrm{g} / \mathrm{min}$.

The haemodynamic effects of the combined drug regimen are summarised in the table. Mean cardiac index increased by $44 \%$ while pulmonary artery end-diastolic pressure fell by $33 \%$. Heart rate was almost unaffected. The systolic arterial pressure fell on average by $16 \mathrm{~mm} \mathrm{Hg}$ from 112 to $96 \mathrm{~mm} \mathrm{Hg}$.

Observations made before, during, and after salbutamolnitroprusside infusion in 11 of the patients are summarised in fig 1 . These confirm that the changes reflected drug effects rather than spontaneous improvement since all variables returned towards control values on withdrawal of the infusion.

Final changes in cardiac index and pulmonary artery end-diastolic pressure were similar regardless of which drug was infused first. Nitroprusside accounted for most of the fall in filling pressure in both treatment sequences, whereas nitroprusside and salbutamol contributed almost equally to the augmented cardiac index (fig 2).
Mean stroke work index for the group was only $14 \mathrm{~g} \mathrm{~m} / \mathrm{m}^{2}$ (range $6-27 \mathrm{~g} \mathrm{~m} / \mathrm{m}^{2}$ ), also reflecting the severity of left ventricular dysfunction in these patients. Despite this, 10 of the group survived to be discharged from hospital. None died within 24 hours of completion of haemodynamic measurements.

Haemodynamic responses to combined salbutamol-nitroprusside regimen. Data are means $\pm S E M$

\begin{tabular}{|c|c|c|c|}
\hline & Control & $\begin{array}{l}\text { Salbutamol + } \\
\text { nitroprusside }\end{array}$ & p Value \\
\hline 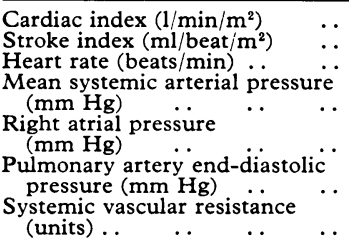 & $\begin{aligned} 1 \cdot 8 & \pm 0 \cdot 1 \\
17 & \pm 1 \\
104 & \pm 5 \\
81 & \pm 5 \\
3 & \pm 1 \\
24 & \pm 1 \\
25 & \pm 1\end{aligned}$ & $\begin{array}{c}2 \cdot 6 \pm 0 \cdot 2 \\
24 \pm 2 \\
107 \pm 5 \\
68 \pm 4 \\
0 \pm 1 \\
16 \pm 1 \\
14 \pm 1\end{array}$ & $\begin{array}{c}<0.001 \\
<0.001 \\
\text { NS } \\
<0.001 \\
<0.001 \\
<0.001 \\
<0.001\end{array}$ \\
\hline
\end{tabular}

Pressures were recorded with reference to sternal angle. Reference to mid-chest would require the addition of about $5 \mathrm{~mm} \mathrm{Hg}$.
Not significant.

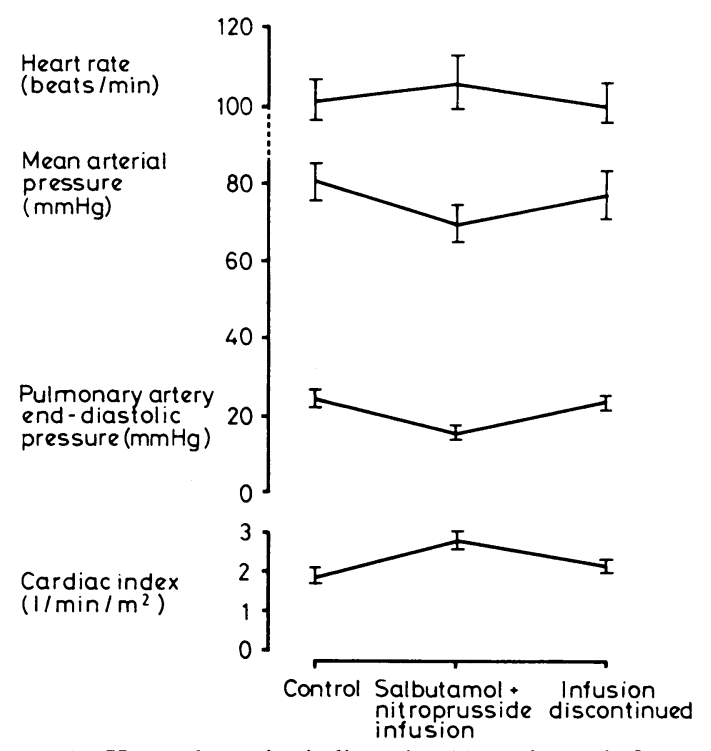

FIG 1-Haemodynamic indices in 11 patients before, during, and after salbutamol-nitroprusside infusion. Values are means $\pm S E M$.

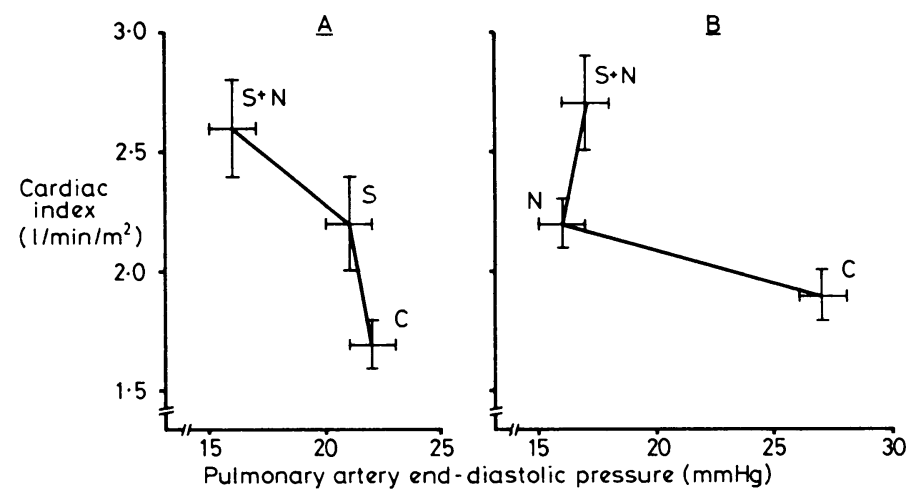

FIG 2-( $A$ ) Effects of salbutamol alone $(\mathrm{S})$ and in combination with nitroprusside $(\mathrm{S}+\mathrm{N})$ on cardiac index and pulmonary artery end-diastolic pressure. Point $C$ represents control values $(n=10)$. $(B)$ Effects of nitroprusside alone $(N)$ and in combination with salbutamol $(S+N)$ on cardiac index and pulmonary artery end-diastolic pressure. Point $\mathrm{C}$ represents control values $(n=10)$. 


\section{Discussion}

Raised left ventricular filling pressure and reduced cardiac output are the principal haemodynamic consequences of extensive myocardial infarction. If severe they will cause pulmonary oedema and cardiogenic shock. As an isolated complication left ventricular failure often responds rapidly to conventional treatment, but when it is refractory or associated with shock the prognosis is poor and treatment unsatisfactory. We have previously shown that in acute myocardial infarction complicated by severe failure salbutamol infusion at $20 \mu \mathrm{g} / \mathrm{min}$ substantially improves cardiac output, ${ }^{2}$ and our findings in this study confirm this observation. The effect is mediated principally by peripheral arteriolar dilatation due to $\beta_{2}$-adrenergic stimulation. Unfortunately left ventricular filling pressure as reflected by pulmonary artery end-diastolic pressure is not affected by salbutamol, and this limits its value as a single therapeutic agent for most patients with a critical haemodynamic state after infarction.

Sodium nitroprusside acts directly on vascular smooth muscle, and unlike salbutamol it reduces both arteriolar and venous tone. The drug has been recommended in the treatment of severe infarction alone,$^{3-6}$ and in combination with inotropes in refractory heart failure, ${ }^{8}{ }^{9}$ because its vascular effects reduce left ventricular filling pressure and produce a variable increase in cardiac output. We expected that sodium nitroprusside and salbutamol would have a useful synergistic action, and our results confirm this.

We were interested to know how far the increase in cardiac output (average 44\%) was due to salbutamol and how far it was due to nitroprusside. The poor clinical condition of our patients precluded prolonged studies with each agent in turn and then combined, but we varied the sequence of treatment. Though we made no attempt to match the groups, the pattern of response was consistent: salbutamol and nitroprusside each accounted for about half the increase in cardiac output irrespective of the order, while nitroprusside accounted for almost all the reduction in filling pressure.

Sodium nitroprusside itself has two of the properties we believe to be valuable in severe infarction-namely, arteriolar and venous dilatation. But the drug has important dose-related disadvantages as a single agent, one of which depends on Starling's observation that with reduction of left ventricular filling pressure cardiac output falls. Though patients with severe heart failure tend to have "flat" left ventricular function curves, a decrease in left atrial pressure below about 10 to 15 $\mathrm{mm} \mathrm{Hg}$ (with reference to sternal angle) adversely influences cardiac output. This effect may occur with nitroprusside sufficiently to overshadow the beneficial effect on output mediated by reduced arteriolar tone. ${ }^{358}$ We therefore took special care not to permit pulmonary artery end-diastolic pressure to fall below $15 \mathrm{~mm} \mathrm{Hg}$, and at this level we observed a small coincident increase in output.

Sodium nitroprusside as a single agent has other disadvantages. A fall in peripheral resistance which is not matched by a concomitant increase in output will further lower blood pressure. This may affect the distribution of blood flow and is likely to worsen renal function if patients are already hypotensive. We did not always prevent this problem, but the average fall in mean arterial pressure of $13 \mathrm{~mm} \mathrm{Hg}$ in our patients was considerably less than that recorded in some comparable series studied with nitroprusside alone. ${ }^{6}$ We prevented excessive tachycardia and observed an average increase in rate of only three beats/min compared with pretreatment values. With strict adherence to our limited objectives in reducing filling pressure (average $8 \mathrm{~mm} \mathrm{Hg}$ ) we could use a relatively low dose of nitroprusside. Cyanide poisoning from contaminants is a dose-related hazard of nitroprusside treatment. ${ }^{10}$ Only five of our patients required more than $50 \mu \mathrm{g} / \mathrm{min}$, and most were at little risk of the hazard since treatment was not usually prolonged.

We believe that combined treatment with salbutamol and nitroprusside, like that with salbutamol alone, ${ }^{2}$ carries little metabolic cost to the heart. The combined effects on blood pressure and heart rate are small and the changes observed would tend to cancel out as determinants of increased oxygen requirement. Likewise changes in contractility and heart size must be small and would act in opposite directions. Therefore, this treatment should not materially increase infarct size by jeopardising the ischaemic myocardium, whose viability depends on a critical balance between oxygen supply and demand.

Facilities for measuring pressures and flow are not always available in units caring for patients with serious complications of myocardial infarction. On the basis of observations in this and other ${ }^{2}$ series we believe that a suitable regimen for refractory failure and low cardiac output can be prescribed without invasive monitoring. This comprises salbutamol in a fixed dose of $20 \mu \mathrm{g} / \mathrm{min}$ together with a dose of nitroprusside below that which causes any but a trivial increase in heart rate or fall in blood pressure. As with all potent vasoactive compounds, infusion must be controlled with a reliable drip counter or infusion pump.

In such a small group of patients it is difficult to make meaningful comments on the effects of treatment on prognosis. Chatterjee et $a l^{7}$ reported a hospital mortality with conventional treatment approaching $80 \%$ in patients with stroke work indices of $20 \mathrm{~g} \mathrm{~m} / \mathrm{m}^{2}$ or less and left ventricular filling pressure over $15 \mathrm{~mm} \mathrm{Hg}$. Eighteen of our 20 patients were in this highrisk group, and nine of these survived. Salbutamol and nitroprusside as combined treatment have an impressive effect on haemodynamics in patients with severe myocardial infarction and refractory left ventricular failure. The possibility that survival may be improved merits further study.

\section{References}

1 Gibson DG, Coltart DJ. Haemodynamic effects of intravenous salbutamol in patients with mitral valve disease: comparison with isoprenaline and atropine. Postgrad Med $\mathcal{F} 1971 ; 47$,suppl 1:40-4.

2 Timmis AD, Strak SK, Chamberlain DA. Haemodynamic effects of salbutamol in patients with acute myocardial infarction and severe left ventricular dysfunction. $\mathrm{Br} \mathrm{Med} \mp 1979$;ii.1101-3.

${ }^{3}$ Franciosa JA, Guiha NH, Limas CJ, Rodriguera E, Cohn JN. Improved left ventricular function during nitroprusside infusion in acute myocardial infarction. Lancet $1972 ; \mathrm{i}: 650-4$.

4 Chatterjee K, Parmley WW, Ganz W, et al. Hemodynamic and metabolic responses to vasodilator therapy in acute myocardial infarction. Circulation 1973;48:1183-93.

5 Armstrong PW, Walker DC, Burton JR, Parker JO. Vasodilator therapy in acute myocardial infarction: a comparison of sodium nitroprusside and nitroglycerin. Circulation $1975 ; 52: 1118-22$.

${ }^{6}$ Kötter V, Von Leitner ER, Wunderlich J, Schröder R. Comparison of haemodynamic effects of phentolamine, sodium nitroprusside, and glyceryl trinitrate in acute myocardial infarction. $\mathrm{Br}$ Heart $\mathcal{f} 1977$; 39:1196-204.

7 Chatteriee K, Swan HJC. Hemodynamic profile in acute myocardial infarction. In: Corday E, Swan HJC, eds. Myocardial infarction. Baltimore: Williams and Wilkins, 1973:51-61.

${ }^{8}$ Stemple DR, Kleiman JH, Harrison DC. Combined nitroprussidedopamine therapy in severe chronic congestive heart failure. Doserelated hemodynamic advantages over single drug infusions. Am $\mathcal{f}$ Cardiol 1978;42:267-75.

- Mikulic E, Cohn JN, Franciosa JA. Comparative hemodynamic effects of inotropic and vasodilator drugs in severe heart failure. Circulation $1977 ; 56: 528-33$.

10 Tinker JH, Michenfelder JD. Sodium nitroprusside: pharmacology, toxicology and therapeutics. Anesthesiology 1976;45:340-54.

(Accepted 27 November 1979) 